\title{
Removal of arsenic and manganese from the tailing storage facility of a gold mine using Vetiveria zizanioides, Bambusa bambos and Pennisetum purpureum
}

\author{
Pantawat Sampanpanish ${ }^{1,2,3^{*}}$ and Panwadee Suwattiga ${ }^{4}$ \\ ${ }^{1}$ Environmental Research Institute, Chulalongkorn University (ERIC), Bangkok 10330, Thailand \\ ${ }^{2}$ Research Program of Toxic Substance Management in the Mining Industry, Center of Excellence on Hazardous \\ Substance Management (HSM), Chulalongkorn University, Bangkok 10330, Thailand \\ ${ }^{3}$ Research Unit of Green Mining Management (GMM), Chulalongkorn University, Bangkok 10330, Thailand \\ ${ }^{4}$ Department of Agro-industry, Food and Environmental Technology, Faculty of Applied Science, King Mongkut's \\ University of Technology North Bangkok, Bangkok 10800, Thailand
}

\begin{abstract}
Phytoremediation is a promising technology to remediate heavy metal contaminated soil. The main objective of this study was to investigate the potential of using Vetiveria zizanioides, Bambusa bambos and Pennisetum purpureum to remove arsenic (As) and manganese (Mn) from the metal (loid) tailings pond of a gold mine. The aerial or aboveground parts (shoots and leaves) and underground parts (roots) of these plants, as well as the metal (loid) tailings soil, were analyzed for the As and Mn contents using the USEPA technique. The samples were collected every 30 d over a 180 d cultivation period. This study has shown that the relative growth rate $(R G R)$ of all three plants' dry weight decreased with increasing cultivation time to $180 \mathrm{~d}$. The results exhibited that P. purpureum had the highest growth rate and accumulated the highest As and Mn levels in the aerial parts at 15.5 and $943.3 \mathrm{mg} / \mathrm{plant}$, respectively. On the other hand, the accumulation of As and Mn in the underground parts were 1.8 and 93.7 $\mathrm{mg} /$ plant, respectively. Moreover, $P$. purpureum is very tolerant to various soil and weather conditions; and it provides abundant biomass. Hence, rather than using it as phytoremediation only, $P$. purpureum could be utilized as biomass feedstock for producing heat and electricity.
\end{abstract}

Keywords: Phytoremediation, phytotolerant, phytotoxicity, gold mine, metalloid

\section{Introduction}

Heavy metal contamination occurs naturally, but especially from anthropogenic activities, such as mining (Niyomthai and Wattanawan, 2014). In mining activities, the soil surface has to be exposed to extract the relevant precious mineral, but these activities can result in heavy metal leaching into the environment. Thailand has one area of open gold mining (Parinyachet and Leepowpanth, 2015), and arsenic (As) and manganese (Mn) are found in association with the gold. With poor mining practice, the leaching of these metal (loid) can adversely affect the environmental quality as well as the physical and mental health of nearby communities (Jaruvakul, 2007).

Heavy metal phytoremediation uses a green plant to extract the heavy metal contaminants from the environment (surface water or topsoil) and accumulate it in the plant tissue (Akkajit, 2015). This is a cost effective method that generates insignificant negative effects on the environment. To maximize the phytoremediation efficiency, the selected green plant species should have a high growth rate and high biomass content, and this biological treatment can be more efficient than the more costly chemical and physical treatment (Tananonchai and Sampanpanish, 2014). Moreover, the green plants should be non-edible in order to prevent the heavy metal contamination from entering into the food chain (Ghosh and Singh, 2005; Sampanpanish, 2015).

In this study, the three non-edible monocotyledon plants of Vetiveria zizanioides (L.), Bambusa bambos (L.) and Pennisetum purpureum (cv. Mott.) were evaluated for their potential to remove $\mathrm{As}$ and $\mathrm{Mn}$ from the tailing storage soil of an open gold mine. The objectives were to study the growth rate and toxicity symptoms of the plants, to investigate the As and Mn uptake efficiency of the three selected monocot species when cultivated in an As and Mn contaminated area and to compare the accumulation of As and $\mathrm{Mn}$ in the three selected plant species.

\section{Materials and Methods}

\section{Site preparation}

The selected study area was the Tailing Storage Facility (TSF) or metal (loid) reservoir in the gold mine area at GPS location $X=676128, Y=1801325$. Soil in the metal (loid) reservior was excavated, each as a $30 \times 30 \mathrm{~cm}$

\footnotetext{
*Email: pantawat.s@chula.ac.th
} 
square with a depth of $30 \mathrm{~cm}$, for planting one plant per plot. At the bottom of each plot, $1 \mathrm{~kg}$ of polymer absorber was placed as a base layer and then $30 \mathrm{~g}$ of chemical fertilizer (15-15-15 NPK formula) which was equivalent to $500 \mathrm{~kg}$ of elements/1,600 square meter was added to the soil since there was no nutrient in the soil in the selected study area. Afterward, plant species with the same size and weight were planted in each experimental plot. The control plots were the experimental plots without fertilizer addition. About $1 \mathrm{~L}$ of water was applied into each plot during 9.00-12.00 am everyday throughout the $180 \mathrm{~d}$ cultivation period. In addition, the fertilizer was added again in the second month of the cultivation to each plot.

\section{Growth rate and phytotoxicity}

The relative growth rate (RGR) of the plants was observed by measurement of the plant dry weight (DW) mass every $30 \mathrm{~d}$ (Hoffmann and Porter, 2002) and was derived using Eq. (1). In addition, phytotoxicity was monitored by visual observation of the monocot leaves as previously reported (Brown et al., 1991) and then recorded. The percentage phytotoxicity was calculated from Eq. (2).

$$
\mathrm{RGR}=\frac{\left[\operatorname{Ln}\left(\mathrm{W}_{2}\right)-\operatorname{Ln}\left(\mathrm{W}_{1}\right)\right]}{\left(\mathrm{t}_{2}-\mathrm{t}_{1}\right)}
$$

Where: $\mathrm{W}_{1}$ and $\mathrm{W}_{2}$ are the dry weight $(\mathrm{g})$ of plants at the beginning and harvesting time, respectively, and $t_{1}$ and $\mathrm{t}_{2}$ are the time (d) at the beginning and harvesting time, respectively.

Phytotoxicity $(\%)=$

$\underline{\left(\mathrm{A}_{0} \mathrm{xB}_{0}\right)+\left(\mathrm{A}_{1} \mathrm{XB}_{1}\right)+\left(\mathrm{A}_{2} \mathrm{xB}_{2}\right)+\left(\mathrm{A}_{3} \mathrm{xB}_{3}\right)+\left(\mathrm{A}_{4} \mathrm{xB}_{4}\right)+\left(\mathrm{A}_{5} \mathrm{xB}_{5}\right) \times 100}$

$$
\left(\mathrm{A}_{r^{\mathrm{x}}} \mathrm{BB}_{r}\right)
$$

Where: A is the number of leaves with toxic symptoms at a different level of toxicity, ranked from non-toxic (A0) to severe (A5), B is the phytotoxicity score from 0 to 5 (B0-B5), Ar is total number of leaves and $\mathrm{Br}$ is the highest phytotoxicity score (5).

\section{As and Mn in the plants and soil samples}

Both the plant and soil samples were collected every $30 \mathrm{~d}$ over the $180 \mathrm{~d}$ cultivation period. Plant samples were first cleaned in tap water and then in deionized water. They were then cut into two parts of aerial and underground parts and then oven dried to constant weight (dry weight) at $105{ }^{\circ} \mathrm{C}$ for $24-48 \mathrm{~h}$. Soil samples were likewise oven dried. Subsequently, each dry sample was ground and meshed to pass through a 10 mesh-sieve, before the As and Mn levels were analyzed using the USEPA 3052 method (US.EPA, 1996) by Atomic
Absorption Spectrophotometry (AAs). The results showed that original soils had As and Mn levels at 50 and 1,670 $\mathrm{mg} / \mathrm{kg}$, respectively. Whereas, all plants had none detectable metal (loid) of As and Mn.

\section{Statistical analysis}

Variation in the As and $\mathrm{Mn}$ accumulation levels was assayed by analysis of variance (ANOVA) and the significanc of any differences between means was tested using Duncan's new multiple range test (DMRT), accepting significance at the 95\% $(p<0.05)$ level. All statistical analyses were performed using the Statistical Package for the Social Science (SPSS) software.

\section{Results and Discussion}

\section{Growth rate}

All three selected monocot species ( $V$. zizanioides, $B$. bambos and $P$. purpureum) showed increase in dry weight of plants biomass with time during the $180 \mathrm{~d}$ cultivation period, having the highest plant biomass at $180 \mathrm{~d}$ (Figure 1). However, the growth of the three monocot species were significantly different between each other $(p<0.05)$, with by far the highest growth (as DW of plant biomass) being observed for P. purpureum, which attained 3,343 g (208.6 g and 3,134.1 $\mathrm{g}$ for underground and aerial parts, respectively), followed by $1,083 \mathrm{~g}$ for $V$. zizanioides (223.3 and $859.3 \mathrm{~g}$ for underground and aerial parts, respectively) and $811 \mathrm{~g}$ for B. bambos (179.2 and $631.7 \mathrm{~g}$ for underground and aerial parts, respectively).

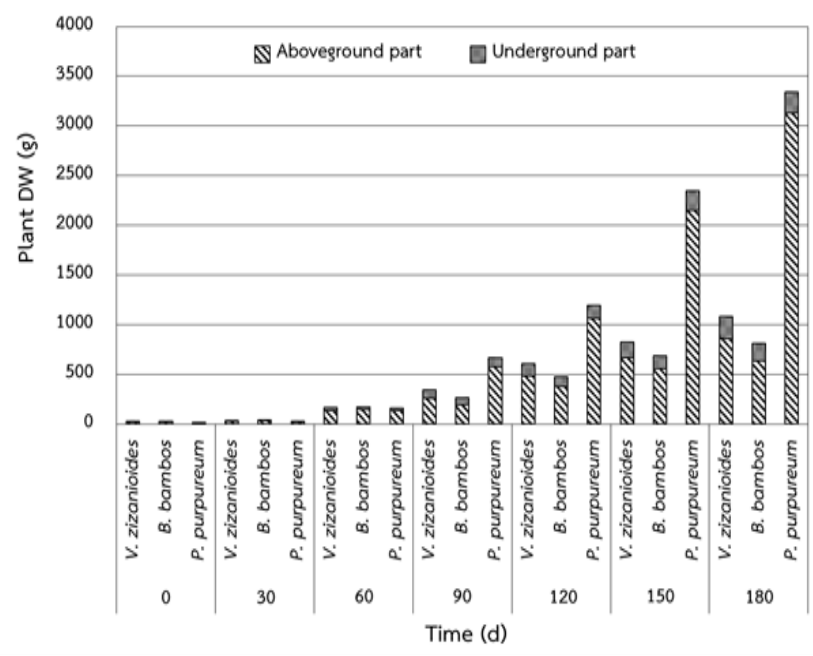

Figure 1: Growth (as DW mass) of the selected plants over 180 d cultivation. Data are shown as mean $\pm S D$, derived from three replicates. Means with a different letter are significantly different $(p<0.05$; DMRT $)$. 


\section{Phytotoxicity}

Within the $180 \mathrm{~d}$ cultivation period, the phytotoxicity level of $V$. zizanioides, $B$. bambos and $P$. purpureum was $53 \%, 56 \%$ and $56 \%$, respectively. The observed symptoms in $V$. zizanioides were the presence of yellow dots at the rim of leaves along with leaf curl, while in $B$. bambos and $P$. purpureum both plants showed some yellow dots at the rim and along all the length of the leaves. This may be due to the phytosynthesis resistance effect, when As and Mn were absorbed and subsequently accumulated in plant tissues (Pangta and Sampanpanish, 2009). This result is in accordance with that reported previously by Sampanpanish et al. (2008), who found that Chromolaena odorata and V. zizanioides (L.) cultivated in heavy metal contaminated soil showed phytotoxicity symptoms, such as white, curled and burnt leaves, due to heavy metal accumulation in the plant tissues.

\section{Correlation between RGR and phytotoxicity}

The RGR of all the three monocots evaluated in this study decreased with an increasing cultivation time over the $180 \mathrm{~d}$ period (Figure 2). This could be due to the resistance process and growth inhibition of plants in order to survive and adjust themselves to tolerate the As and $\mathrm{Mn}$ contaminants at a certain level. In addition, the highest RGR of all three monocot species were significantly different to each other $(p<0.05)$, but reached maximum at $60 \mathrm{~d}$ of cultivation and decreased steadily with cultivation time thereafter, with the RGR of $P$. purpureum at $180 \mathrm{~d}$ cultivation being lower than the initial RGR at $30 \mathrm{~d}$.

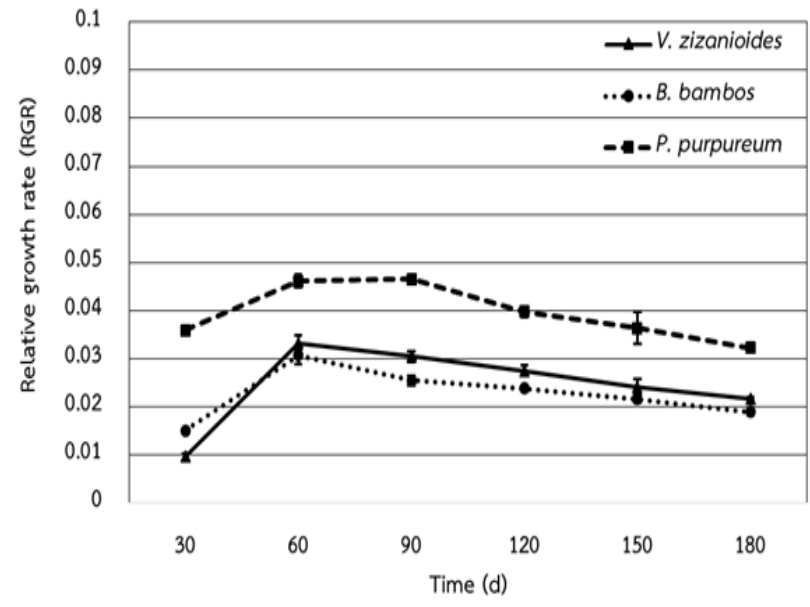

Figure 2: The RGR of the three selected monocots. Data are shown as mean $\pm \mathrm{SD}$, derived from three replicates. Means with a different letter are significantly different ( $p<0.05$; DMRT).

\section{Total As accumulation in plants}

For the total As accumulation in the plants, the highest As accumulation in the aerial part was $4.9 \mathrm{mg} / \mathrm{kg} \mathrm{DW}$ in $P$. purpureum after 180 d cultivation, followed by $B$. bambos and $V$. zizanioides at 4.7 and $4.6 \mathrm{mg} / \mathrm{kg} \mathrm{DW}$, respectively. For As accumulation in the underground parts, in contrast the highest As accumulation was found in $V$. zizanioides at $11.5 \mathrm{mg} / \mathrm{kg} \mathrm{DW}$, followed by $B$. bambos and $P$. purpureum at 10.6 and $8.6 \mathrm{mg} / \mathrm{kg} \mathrm{DW}$, respectively.

In addition, the total As accumulation in plant material was higher in the aerial parts than in the underground parts of all three monocots after $180 \mathrm{~d}$ of cultivation. The highest level of As accumulation (15.5 mg/plant) was found in the aerial parts of $P$. purpureum, followed by $V$. zizanioides and $B$. bambos at 4.0 and $3.0 \mathrm{mg} / \mathrm{plant}$, respectively. For As accumulation in the underground parts, the highest level was in $V$. zizanioides (2.6 $\mathrm{mg} / \mathrm{plant})$, followed by $B$. bambos and $P$. purpureum at 1.9 and $1.8 \mathrm{mg} / \mathrm{plant}$, respectively. Overall, $P$. purpureum had the highest total As accumulation in the whole plant, followed by $V$. zizanioides and $B$. bambos, respectively. That, the aerial parts of the plants played an important role in the As uptake and accumulation may be due to the markedly higher biomass of the aerial parts than the underground parts, ranging from 3.5-fold for B. bambos to 15 -fold for $P$. purpureum. The total As accumulation per plant is shown in Figure 3.

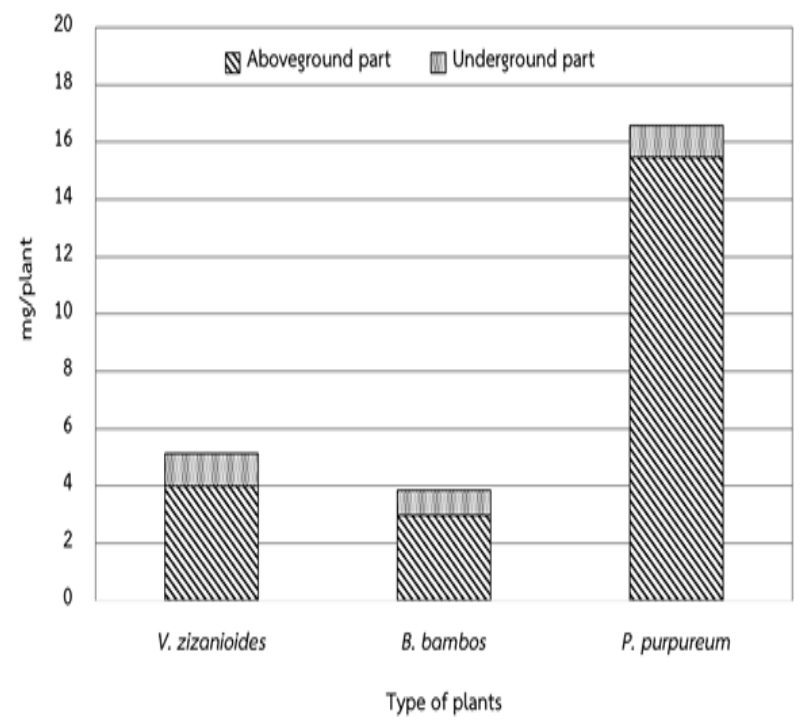

Figure 3: Total As accumulation level in each plant after 180 d cultivation. Data are shown as mean \pm SD, derived from three replicates. Means with a different letter are significantly different $(p<0.05$; DMRT). 


\section{Total Mn accumulation in the plants}

The level of Mn accumulation in the plants after $180 \mathrm{~d}$ cultivation was higher in the underground parts of both $V$. zizanioides and $P$. purpureum than in the aerial parts. However, there was no significant difference in the $\mathrm{Mn}$ accumulation level between the underground and aerial parts of B. bambos. The highest $\mathrm{Mn}$ accumulation level (301.0 mg/kg DW) was found in the aerial part of $P$. purpureum, followed by $B$. bambos and $V$. zizanioides at 290.2 and $182.9 \mathrm{mg} / \mathrm{kg}$ DW, respectively. Moreover, the underground parts of $P$. purpureum clearly had the highest Mn accumulation level ( $450.5 \mathrm{mg} / \mathrm{kg} \mathrm{DW})$, followed by $V$. zizanioides and B. bambos at 309.9 and $278.5 \mathrm{mg} / \mathrm{kg} \mathrm{DW}$, respectively.

Considering the total $\mathrm{Mn}$ accumulation in different parts of the plants after $180 \mathrm{~d}$ cultivation, the aerial parts of the three monocots accumulated more $\mathrm{Mn}$ than the underground parts, with the highest level in $P$. purpureum followed by $B$. bambos and $V$. zizanioides at $943.3,183.5$ and $157.2 \mathrm{mg} /$ plant, respectively. Within the underground parts, $P$. purpureum accumulated the highest Mn level at $93.8 \mathrm{mg} / \mathrm{plant}$, followed by $V$. zizanioides and B. bambos at 69.0 and $50.2 \mathrm{mg} /$ plant, respectively. The total $\mathrm{Mn}$ accumulation per plant is shown in Figure 4.

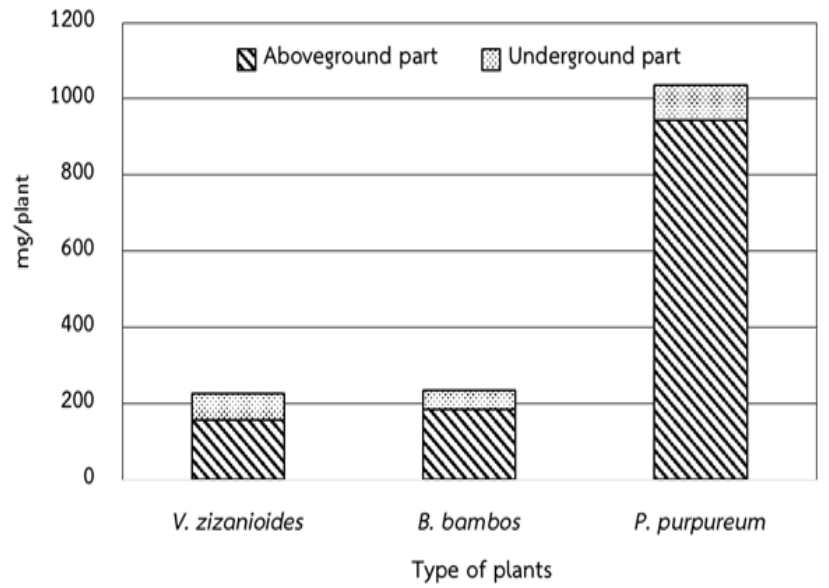

Figure 4: Total Mn accumulation level per plant after 180 d cultivation. Data are shown as mean \pm SD, derived from three replicates. Means with a different letter are significantly different $(p<0.05$; DMRT).

Overall, of the three plant species studied, $P$. purpureum had the highest capacity for Mn accumulation. This may reflect its fibrous root system which has a complex structure of permanent tissue that can uptake and subsequently transport soluble $\mathrm{Mn}^{2+}$ from the soil solution through the xylem and partially through the phloem to various parts of the plant. Xylem is recognised as an important part of the plant that has a major function in transportation of both water and other nutrients in ion form or as a chelate (Tananonchai and Sampanpanish, 2014). For example, the transportation of manganese citrate or malate from the root to various other parts of the plant by conduction (Tananonchai and Sampanpanish, 2014; Nadeem et al., 2016.). The transportation of nutrients through the phloem is different for different parts of the plant, which might be due to greater ease of Mn transport in the underground parts than in the aerial parts (Mazzolini et al., 1985). Therefore, Mn accumulation per kg DW plant tissue in the underground parts tended to be higher than in the aerial parts, but overall the total Mn accumulation per plant was higher in the aerial parts due to the greater above ground mass.

\section{Residual level of As and Mn in the cultivated soil}

The As and Mn levels in the soil decreased over the $180 \mathrm{~d}$ cultivation period (Figure 5). This result conformed to the increasing As and $\mathrm{Mn}$ accumulation level in the plants over the same period. Of the three plants, $P$. purpureum had the highest capacity to deplete the soil of residual As and $\mathrm{Mn}$, in accordance with its highest As and $\mathrm{Mn}$ accumulation compared to $V$. zizanioides and $B$. bambos.

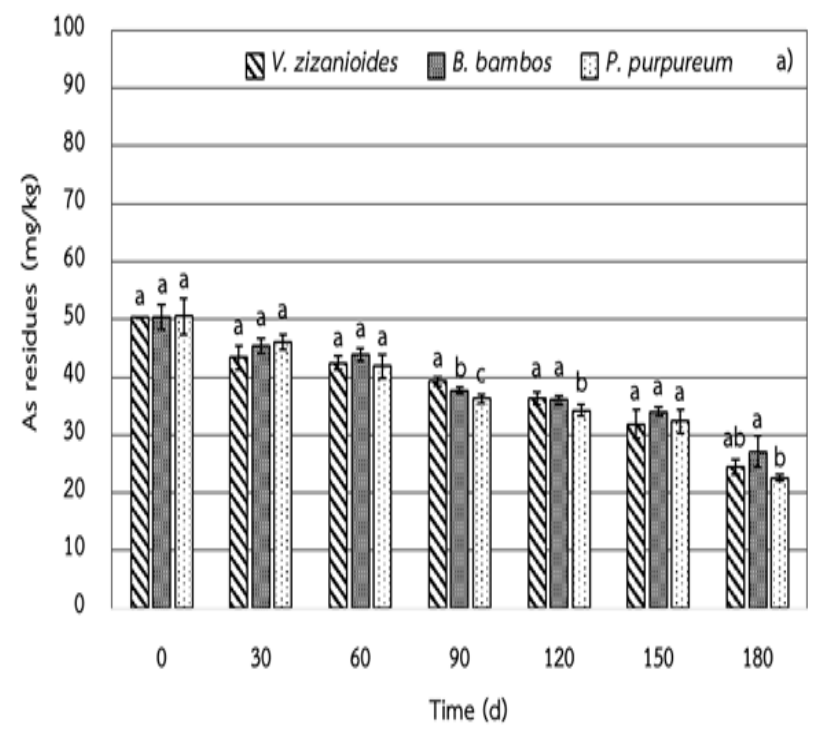

Figure 5: Residual (a) As and (b) Mn concentration in the soil over the $180 \mathrm{~d}$ cultivation period with the indicated plant species. Data are shown as mean $\pm \mathrm{SD}$, derived from three replicates. Means with a different letter are significantly different $(p<0.05$; DMRT). 


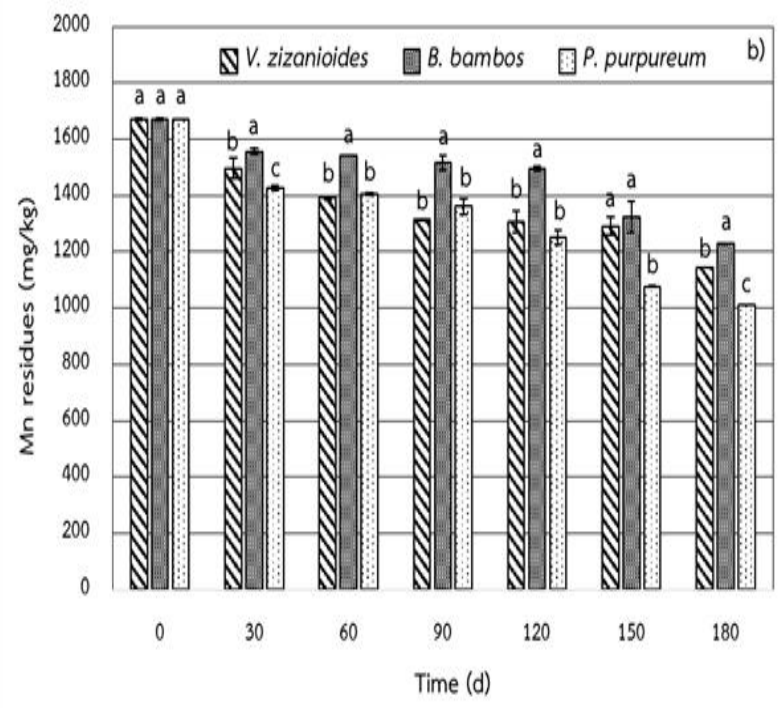

Figure 5: Residual (a) As and (b) Mn concentration in the soil over the $180 \mathrm{~d}$ cultivation period with the indicated plant species. Data are shown as mean $\pm \mathrm{SD}$, derived from three replicates. Means with a different letter are significantly different $(p<0.05$; DMRT). (Cont.)

\section{Conclusion}

All plants in this study should be cultivated until it can no longer deplete the contaminated metals or until the contaminated metals are below the standards and safety. A higher proportion of metal (loid) was accumulated in the aerial parts rather than in the underground parts of each plant since the shoot parts had a by far higher biomass at 3.5- to 15 -fold by DW. Of the three studied plants, $P$. purpureum showed the highest accumulation level of As and $\mathrm{Mn}$ as well as the highest metal (loid) removal efficiency from the tailing storage soil, which was reduced continuously over the $180 \mathrm{~d}$ cultivation period. This was likely to be due to it having the fastest growth rate (nearly double than those of the two other species).

In the case of As and Mn toxicity to P. purpureum, yellow leaves and some leaf curl was observed, but this did not have an effect on the growth rate during the $180 \mathrm{~d}$ cultivation period. Moreover, the biomass increased (as DW) continuously across the $180 \mathrm{~d}$ cultivation period, and so $P$. purpureum appears to be a suitable plant for As and Mn removal in this contaminated site. However, it should be noted that the limitation of using $P$. purpureum in phytoremediation is its short fibrous roots, and so it would only have this high potential for metal (loid) removal when applied in a shallow tailing storage pond. In addition to its high growth rate, biomass and metal (loid) accumulation, $P$. purpureum can be utilized as a feedstock for producing electricity (Buranasin, 2015).

\section{Acknowledgements}

The authors thank Nuttha Kongpol, Anotai Kowit and Wacharin Sirisopol, students from the Department of Agroindustry, Food and Environmental Technology, Faculty of Applied Science, King Mongkut's University of Technology North Bangkok, for help with sample collection and lab analyses. In addition, Aekkacha Tananonchai and Jatuvit Kuptasin evaluated and analyzed the data statistically. The Office of Higher Education Commission (OHEC) and the S\&T Postgraduate Education and Research Development Office (PERDO) provided financial support of the Research Program, and the Ratchadaphiseksomphot Endowment Fund, Chulalongkorn University, funded the Research Unit. We express our sincere thanks to the Environmental Research Institute (ERIC) and the Center of Excellence on Hazardous Substance Management (HSM), Chulalongkorn University, for their support in terms of facilities and scientific equipment.

\section{References}

Akkajit, P. 2015. Review of the current situation of Cd contamination in agricultural field in the Mae Sot district, Tak province, Northwestern Thailand. Applied Environmental Research 37(1): 71-82. doi: http://dx.doi.org/10.14456/aer.2015.9

Brown, J.C., D. Von, C. Jolley and C. Mel Lytle. 1991. Comparative evaluation of iron solubilizing substances (phytosiderophores) released by oats and corn: Ironefficient and iron-inefficient plants. Plant and Soil 130 (1/2): 157-163.

Buranasin, N. 2015. Energy grass: Mott Dwarf Napier grass (Pennisetum purpureum CV. MOTT) (Online. Source: http://www.parliament.go.th/ewtadmin/ewt/parliament _parcy/ewt_w3c/ewt_dl_link.php?nid=30598[11 January 2016]

Ghosh, M. and S.P. Singh. 2005. A review on phytoremediation of heavy metals and utilization of its byproducts. Applied Ecology and Environment Research 3 (1): 1-18.

Hoffmann and Porter, 2002. Avoiding bias in calculations of relative growth rate. Annals of Botany 90 (1): 37-42. doi: https://doi.org/10.1093/aob/mcf140

Jaruvakul, P. 2007. Cyanide with Mining Industry. Bureau of Primary Industries. $1^{\text {st }}$ Printing. Bangkok: Department of Primary Industries and Mines, Bangkok, Thailand. 
Mazzolini, A.P., C.K. Pallaghy and G.J.F. Legge. 1985. Quantitative microanalysis of $\mathrm{Mn}, \mathrm{Zn}$ and other elements in mature wheat seed. New Phytologist 100: 483-509. doi: 10.1111/j.1469-8137.1985.tb02796.x

Nadeem, S.M., M. Naveed, M. Ayyub, M.Y. Khan, M. Ahmad and Z.A. Zahir. 2016. Potential, limitations and future prospects of Pseudomonas spp. for sustainable agriculture and environment: A review. Soil \& Environment 35 (2): 106-145.

Niyomthai, S., and A. Wattanawan. 2014. Sustainable mining in Thailand: Paradigm shift in environmental management. Applied Environmental Research 36 (1): 55-63. doi: http://dx.doi.org/10.14456/aer.2014.13

Pangta, S., and P. Sampanpanish. 2009. Use of Ananas comosus (L.) Merr. as indicator for toxicity of chromium and lead in contaminated soil. In Proceeding of the $2^{\text {nd }}$ CUTSE International conference 2009 on Science and Engineering for Sustainable Development (CUTSE09), Curtin University of Technology, Sarawak, Malaysia, November 24-25, 2009, 2013.
Parinyachet, S. and Q. Leepowpanth. 2015. A study of residual cyanides and potential stabilities in tailings storage facility of gold mining operation. Applied Environmental Research 37 (1): 11-18. doi: http://dx.doi.org/10.14456/aer.2015.5

Sampanpanish, P., W. Chaengcharoen and C. Tongcumpou. 2008. Heavy metals removal from contaminated soil by Siam Weed (Chromolaena odorata) and Vetiver grass (Vertiveria ziza nioides). Research Journal of Chemistry and Environment 12 (3): 23-34.

Sampanpanish, P. 2015. Phytoremediation. $1^{\text {st }}$ Printing. Bangkok: Chulalongkorn University Press.

Tananonchai, A. and P. Sampanpanish. 2014. Effect of EDTA and DTPA on cadmium removal from contaminated soil with water hyacinth. Applied Environmental Research 36 (3): 65-76. doi: http://dx.doi.org/10.14456/aer.2014.25

US.EPA. 1996. SW-846 Test Method 3052: Microwave Assisted Acid Digestion of Siliceous and Organically Based Matrices (method 3052). Washington D.C., United States of America. 